\title{
Institutional practices and planning for walking: a focus on
}

\section{built environment audits}

Courtney Babb ${ }^{1}$ and Carey Curtis ${ }^{1}$

1 Department of Planning and Geography, Curtin University, Perth, Australia

Corresponding email: C.Babb@curtin.edu.au

Courtney Babb is a lecturer in the Department of Planning and Geography, Curtin University, Western Australia, where he teaches units in transport planning and governance in planning. His research interests focus on the social sustainability of cities, mobility and accessibility, transport policy, travel demand management, and issues of governance in urban planning.

Carey Curtis is Professor of City Planning and Transport, Director of the research network Urbanet, Visiting Professor University of Amsterdam. Her research interests cover land use planning and transport planning, including a focus on city form and structure, transit oriented development, personal travel behaviour, accessibility planning, institutional barriers to sustainable transport, governance and transport policy. She has published over 90 papers, book chapters and books and has won five Australian Research Council research grants. Carey is Chair of the International Editorial Board of the Journal 'Urban Policy and Research' and a research articles Editor; she is also a member on the international editorial board of the Journal of Transport Land Use and a member of the Board of the World Society of Transport and Land Use Research. Carey is a member of the Planning Institute Australia and the UK Royal Town Planning Institute. 


\begin{abstract}
Built environment audits, part of the ‘toolbox’ for planning multi-modal urban transport systems, are used to evaluate the walkability of streets. Whereas the methodological features of audits have attracted attention from planning research, little attention has been paid to the institutional contexts where audits are developed and used. Drawing on literature on audit culture in contemporary institutions and on expert interviews with audit developers and professionals in Australia and New Zealand working with walking audits, three questions are addressed: Who uses walkability audits? How are they used? What substantive changes emerge from auditing practice? The knowledge of practice of auditing the built environment for walking is underdeveloped. While planners, engineers and advocates consider built environment audits useful in different ways, of concern is the use of audits to rationalize limited resources already devoted to infrastructure for walking, rather than produce substantive changes to the quality of the built environment for walking.
\end{abstract}

\title{
Keywords.
}

Walking; built environment audits; audit culture; automobility

\section{Introduction}

At the global, national and local scales a culture of automobility has not only transformed the physical scale and form of urban space, but has also reconfigured the social ecology of cities (Martin, 2002). The promise of automobility is based on the freedom to be mobile, requiring speed and flexibility in order to achieve this. For the promise of automobility to be realised, motorised vehicles require road space for movement at particular speeds (Appleyard, 1972). Accommodating mobility has underpinned traditional road planning practice evident in transport policy approaches 
focused on increased road capacity and the management of demand to ensure efficient mobility for cars (Banister, 2002).

Urban land use and transport planning policy has increasingly employed the objective of increasing rates of walking as a means to mitigate the impact of automobile dependency on urban environments, economies and quality of life (Curtis and Punter, 2004). Planning for walking has attracted increased policy attention due to the recognition that resilient and sustainable cities are based on multi-modal transport systems (Mees, 2010; Banister, 2008). The goal of multi-modal mobility has emerged in response to the negative consequences of a century of automobility and the sociospatial changes that have resulted from the dominance of cars and other motorized vehicles in contemporary urban environments (Urry, 2004). Shaping urban environments to sustain walking as a part of people's routine travel activity underpins neo-traditionalist modes of planning, linking increased rates of walking to a general conviviality of urban life (Gehl, 2010; Southworth, 2005). Additionally, health agencies promote increased rates of walking and good environments for walking as policy goals, suggesting everyday trips made by walking provide the opportunity for minimum recommended rates of physical activity to be incorporated into daily routines (Giles-Corti and Donovan, 2002).

There are a number of ways planning practice can contribute to improving the quality of built environments for walking. The design of new urban areas and neighbourhood scale planning - street network design, pedestrian infrastructure, the diversity of land uses and urban density - can provide increased opportunities for walking in newly developed neighbourhoods (Christian et al., 2013). Planning for walking is also critical 
in existing urban areas where there is more pressure on existing urban space and infrastructure. However, Patton (2007) suggests that the rights to mobility asserted by pedestrians and automobiles are incommensurable in increasingly constrained urban streets and trade-offs are necessary. Historically, these trade-offs have been in favour of the car rather that the mobility of alternative modes, such as walking and cycling (Whitelegg, 1997). Trade-offs are made in the name of maintaining prescribed speeds and volumes of vehicles on roads (McCann, 2013). Advocating, monitoring, management and an integrated governance approach based on democratic participation can mitigate conflict between modes of travel inherent in spatially constrained multimodal transport systems (Booth and Richardson, 2001). A further challenge for planners is that improvements to the built environment for walking may not necessarily lead to increased rates of walking, as automobility appeals not only to the perceived convenience of speed and flexibility of travel, but also to emotions, bodily comfort and the expression of identity (Hagman 2006; Kent 2014).

To aid the management of urban space for walking, planners have developed a range of evaluative and analytic tools. An example is built environment audits, which are increasingly being used as a part of the planner's 'toolbox'. These are tools that provide a formal framework for the evaluation of streets and places, such as parks, schools and workplaces, for their level of support for walking, cycling or physical activity. Audits record the presence or absence of infrastructure, assess the quality of existing infrastructure and elicit auditor's subjective responses to the quality of the built environment for factors such as safety and aesthetics (Moudon and Lee, 2003). Audits can be used to identify issues and places where planners can direct policy and planning 
attention. Audits, therefore, potentially have an important role in the evaluation and ongoing monitoring of the quality of urban environments for walking.

Built environment audit methodologies have been the focus of research (Day et al., , 2006; McMillan et al., 2010; Hoehner et al., 2006), however there has been little research on how audits are used in practical planning contexts and whether they are an effective means of delivering multi-modal transport systems. This paper aims to address this gap in knowledge by exploring the institutional context where built environment audits are developed and used. Institutions are the "social rule structures" that enable transactions and dialogue between agents and organisations when addressing policy issues (Rietveld and Stough, 2004). The institutional dimension of transport planning has become an important focus for policy-makers, planners and researchers seeking to understand how policy is implemented, how planning is conducted, and how institutional approaches can contribute to transitions to more sustainable modes of urban mobility (Curtis and Low, 2012). To be effective in planning for multi-modal transport systems, audit tools need to contribute to substantive change that leads to better cities to walk in and more walking. The institutional context - the organisational settings where audits are developed, the problems that audits are employed to address, the technical characteristics of audits, and the tacit knowledge employed by auditors is a critical juncture for this transition to walking-friendly cities. In this paper we explore the institutional context and practice of built environment audits in Australia and New Zealand. Who uses walkability audits? How are they used? And what substantive changes emerge from auditing practice? 


\section{The importance of institutions in planning for multi-modal transport}

\section{systems}

The culture, spaces and everyday practices of modes of mobility are maintained and reproduced through the historical and contemporary socio-spatial, technical and economic systems (Beckmann, 2004). For the dominant regime of automobility these systems include the planning, provision and regulation of roads (Merriman, 2006), globalized car manufacturing and road building industries (Urry, 2004), the allocation and financing of space for parking in spatially constrained cities (Shoup, 2011), and the cultural capital associated with car ownership and use (Steg, 2005). Urban institutions have also been implicated in the reproduction of car-dominated environments (Curtis and Low, 2012). Institutions are the collection of practices, actors, the relationships between them, and rules that shape behaviour and decision-making related to particular domains (Rietveld and Stough, 2004), such as the built environment, transport networks, and social organisation of local environments. Rietveld and Stough (2004) outline four types of institutions: actors, governance, informal and formal. Actors refer to the individuals and organisations, including the resources allocated to addressing relevant issues, operating within a policy domain. Institutional actors draw on common types of knowledge to address planning problems - contextual, scientific and technical (Rydin, Amjad and Whitaker, 2007). Governance institutions are the relationships between various state, civil and market actors in a policy domain. These relationships may take the form of policy coalitions or manifest in conflict between actors with differing policy interests. Informal institutions are made up by the norms, practices and traditions governing relevant actors' behaviour and decision-making. Finally, formal institutions are the codified laws, statutes and regulations that set out rules for conduct 
and communication. Fischer (2003, p.28) captures the importance of institutional factors in shaping planning and political decision-making, stating that by:

“(s)upplying them with regularised behavioural roles, standards of assessment, and emotive commitments, institutions influence political actors by structuring or shaping the political and social interpretations of the problems they have to deal with and by limiting the choice of policy solutions that might be implemented.”

Institutional frameworks of transport planning shape the policy development, planning and management of urban streets. Dudley and Richardson (1996) have argued in their analysis of British roads policy that the institutional arena is an important site for the type of radical policy change that is necessary for the emergence of multi-modal transport systems. Whilst there has been recent academic attention regarding broader transport institutions, there has been little reported on institutions relevant to walking.

To begin to understand the institutional dimension of planning for walking it is useful to define the types of actors engaged in planning to increase rates of walking and improve the quality of the built environment for walking. According to Haas (1992, p.3) actors belong to different epistemic communities, “a network of professionals with recognized expertise and competence in a particular domain and an authoritative claim to policy-relevant knowledge within that domain or issue-area”. Members of epistemic communities are often not co-located, yet attain membership of the community through shared knowledge frameworks, professional identities and practices. The epistemic communities can draw on distinct and often contradictory institutional elements such as bodies of discourses, rules, structures and technical instruments, such as audits, for legitimacy. As Patton (2007) argues the diverse range of professionals charged with 
shaping and managing the streets for multi-modalities - car, bicycle and feet- are often driven by very different and competing rationalities. Facilitating mobility for one mode may constrain mobility for another.

Three epistemic communities operating within the habitus of walking are the focus of this research: travel behaviour change planners, advocates for walking, and transport engineers.

Planners adopting travel behaviour change approaches seek to facilitate a shift from car-based to active modes of transport by shaping personal decision-making regarding travel (Taylor and Ampt, 2003). A combination of information about existing travel options, feedback and evaluation of existing travel activity, public awareness campaigns and events and incentives often form the basis of travel behaviour change programs. This approach, according to Schwanen, Banister and Anable (2012, p. 522) is representative of contemporary governing practices that attempt to "mould the context of individuals' decision-making whilst also increasing the range of available choices for shaping his/her own life”. The formation of institutional relationships of travel behaviour change planners requires local knowledge of the settings where decision-making about travel behaviour takes place, such as households, schools and workplaces. The capacity of behaviour change programs to address significant problems in contemporary societies has been subject to debate. Travel behaviour change programs have been found to be successful in facilitating some individuals' changes to more sustainable modes (Brog et al., 2009.) However, Webb (2012) has suggested behaviour change planning has little potential to address behaviour that contributes to systemic societal crises such as climate change, including shifting to less 
carbon-emitting transport systems. Shove (2010) similarly considers that behaviour change programs avoid the more significant social and economic structures that drive individual decision-making about behaviour, ultimately obscuring the underlying mechanisms that reproduce unsustainable practices.

Organisations and individuals advocating for issues related to walking are members of another epistemic community. Advocacy for walking involves non-government agents acting within both formal and informal capacities to shape community and government activity towards creating walkable urban streets and places. Advocacy positions draw on a number of institutional frames encapsulated in what Blomely (2010) refers to as civic humanist approaches to the street. Civic humanism is an "ontology centred on human capabilities and inter-relationships, with a broad ethical commitment to human flourishing in the here and now" (Blomley, 2010, p.17). Civic humanism focuses on streets as public, democratic space. Advocacy for walking usually involves a range of strategies and tactics, including the provision of information, political lobbying and management of events and forums to draw attention to issues relevant to walking. Advocacy for active travel can operate across organisations, within organisations, and within professions (Richards et al., 2010). In doing so, advocacy bridges institutional domains, drawing on democratic claims for increased civic power within technical public institutions that shape street space. Political advocacy for walking is critical for the implementation of active travel policies in resource constrained public and civic organisations (Lyons et al., 2013) and path-dependent institutional cultures that have traditionally favoured automobility (Curtis and Low, 2012). 
Traffic engineering encompasses the design and management of the physical and operational features of the street for flow, efficiency and safety. Traffic engineers have a substantial role in shaping the quality of the built environment for walking. Blomely (2007) argues that "traffic logic", with its task of maintaining the circulation of objects and bodies in streets, is so widely accepted and its assumptions often unquestioned that it has become naturalized and its practices made invisible. Despite this lack of attention, traffic engineering has a profound influence on walking, as streets are rendered vulnerable to traffic logic. Again, Blomley (2010) refers to the prioritization of the functional elements of the street over elements that represent the street's capacity as a public realm or urban commons as the ‘pedestrianisation' of the street. The public good according to the governing agents associated with pedestrianism- the local municipality or state departments - is predominantly unimpeded circulation of bodies and objects within the street. In contrast to the psychological and behavioural underpinnings of travel behaviour change approaches and the political nature of advocacy, traffic engineering values the technical and physical dimensions of streets rather than the place-function of the street (Curtis and Tiwari, 2009).

\section{Institutions, planning tools and walking: built environment audits}

Walking audits are increasingly employed by each of these epistemic communities for addressing the quality of urban environment for walking. Audits are examples of planning tools, the "range of instruments, mechanisms, tools and actions that policymakers can deploy in response to particular problems and challenges” (Tiesdell and Adams, 2011, p.11). The focus on tools is important as it provides a particular insight into the institutional context of planning for walking. Anthropologist Tim Ingold (2011, p.56) has noted, “(n)o object considered purely in and for itself, in terms of its intrinsic attributes alone can be a tool. To describe a thing as a tool is to place it 
in relation to other things within a field of activity". The fields of activity where planning for walking takes place - the development of plans, the evaluation of problems, and the interaction between planning agents - are shaped in part by the methodological characteristics of tools and the tacit knowledge of the practitioners employed when using planning tools. The tools with application to walking in cities have, in one sense, emerged from the range of tools used to monitor and evaluate systems of automobility. Tools such as 'Level of Service' instruments that measure levels of congestion on roads have been adapted for the purposes of evaluating the quality of streets and paths for pedestrians (Kim, Choi and Kim, 2013).

Built environment audits are tools that facilitate the systematic evaluation of the walkability of urban environments. The recent re-emergence of links between urban planning and health has led to a proliferation of auditing tools used to evaluate the supportiveness of built environments for physical activity, walking, cycling and play. In 2015, the Robert Wood Johnson Foundation’s Active Living Research, a leading U.S. public health research organisation had thirty eight observational surveys and audit tools listed on its website (http://activelivingresearch.org/). Accompanying the development of these auditing tools has been a considerable body of research on the methodological aspects on audits (Clifton et al., 2007; Day et al., 2006; Pikora et al., 2002). The modus operandi of this research has been to establish valid, reliable and practical tools to capture a range of relevant built environment variables for analysis of travel behaviour decision-making. The reasoning underpinning much of this work is that by using valid and reliable auditing techniques to inform an evidence base of the types and features of built environment most conducive to walking, policy makers and planners can then adapt strategies and policy settings to realize these built 
environments. Whereas the methodological basis of built environment audits has been extensively explored, there has been little research into the practical application of audits to policy problems within institutional settings. An exception is the work by Lewis (2012) who provides insight into the moral dimensions of built environment audits so that audit developers may make ethically informed decisions when designing audits to inform policy development and planning.

There has been little attention given to the link between built environment audits and the broader audit culture that characterizes contemporary institutions. The term audit culture has been invoked to reflect the widespread application of financial auditing techniques outside the traditional accounting profession from where they emerged. Auditing techniques have been integrated within a range of institutional practices such as corporate social accounting (Gray, 2002; Spence, 2009), educational performance metrics (Shore, 2008), environmental regulation (Power, 1997), organisational management (Power, 2004) and sustainability evaluations, evident in ecological footprint measures. In this broad field of practice, auditing refers to methods and practices that verify the status or evaluate the quality of performance of individuals, organisations or systems, usually against defined standards and norms. They are used as external indicators to measure and monitor the function and health of systems, improve the transparency of public organisation operations, or make auditors accountable for their actions (Spence, 2009). According to Shore (2008, p.279) these "routine systems of financial management design to verify budgets and ensure organisations comply with administrative norms and regulations” have led to profound changes in organisational culture and social practice, and have become a "new form of hegemonic governance”. Audits serve as effective tools for self-monitoring and self- 
evaluation within organisations and therefore are compatible with the central tenets of neo-liberal governance. Public, private and civic organisations have increasingly made use of audits to internalize the management of 'standards' 'efficiency', 'quality control' and 'risk analysis'.

The naturalized status of audits within an increasingly diverse range of institutional practices has much to do with their ability to draw on technical rationality to support claims for legitimacy and accountability in collective and political realms, often characteristic of streets and places for walking. Power (1995, p.318) suggests, "the 'technicality' of audits is a product of a multiplicity of 'symbolic' resources invoked to give order and rationality to practice”. One of the primary symbolic resources invoked by auditing practice is their appeal as instruments of science based on claims to higher order, abstracted knowledge (Power 1995). As Porter (1995) suggests, techniques of measurement and quantification tools such as audits codify local and tacit knowledge of everyday experience within these formal systems of abstracted knowledge. For walking, higher order knowledge is what Lewis (2012) refers to as the normative set of spatial characteristics and social arrangements that are held by planners to be supportive of walking. Audits can potentially be a powerful resource for community groups and advocacy efforts to improve the quality of streets for walking. However there are barriers to the use of tools in more democratic modes of governing. According to Power (2004) there can sometimes be a disjuncture between the social or policy demands for what is to be measured and the capacity of tools and techniques to measure. Further development of the technological basis of audit tools, therefore, may not be sufficient in realizing audits democratic potential. Walking audits have the capacity to transform 
the localized and direct knowledge of walking environments into formal institutions and consequently reframe community evaluations of walking.

\section{Research Approach}

We explore the institutional contexts where audits are developed and used, reflecting on the role of walkability audits within the broader audit culture that characterizes contemporary institutions. Two questions frame the research design and analytic approach: how do planning practitioners perceive audits to be useful in planning practice; and what are planning practitioners' reflections on the development and use of audits in practice? We examine practice in Australia and New Zealand as the experience of planning for walking in these countries share a common institutional context. Here planning is conducted at the national (NZ), State (Australia) and local government level. Aspirations to integrating land use and transport planning have been present since the 1990s particularly focussed on a desire to reduce car dependency and increase travel by public transport, cycling and walking. This is evident in the development of strategic policy (Transit Oriented Developments and subdivision design, for example the Liveable Neighbourhoods policy in Western Australia); operational planning policy (development control, for example requiring cycle infrastructure in buildings and pedestrian infrastructure); and in street design. Australia and New Zealand (ANZ) transport agencies are also represented by a common association (Austroads), which provides guidelines and technical insight into urban transport systems and infrastructure provision.

Since the mid 1980's the institutions that govern various urban domains in ANZ housing, services and urban amenities, as well as transport - have increasingly adopted neoliberal modes of governance, characterised by the adoption market-based 
administrative mechanisms and service and infrastructure provision driven by demand from consumers, rather than forward planning according future need (Gleeson and Low, 2000). Furthermore ANZ cities are characterised by high mode share for car travel (around $80 \%$ of journeys to work are by car) and low mode share for travel by walking (Mees and Groenhart, 2013; Rose et al., 2009). There is great potential for mode change: on the basis of distance, two thirds of all car trips could be undertaken by walking, cycling or public transport (Curtis, 2001); even very short journeys that could be undertaken on foot are often undertaken by car.

A review of audit tools and interviews with built environment audit developers and audit practitioners in ANZ was undertaken. A web search of national and state government agencies and allied organisations identified six walking audit forms promoted to local government planners ${ }^{1}$ and/or community members to use to evaluate walkability across three Australian state government jurisdictions and New Zealand. To further understand the formal and structural nature of walking audits, a comparative review of the walking audits was undertaken.

Expert interviews were conducted in order to better understand the contextual and tacit knowledge relating to perceptions of auditing the built environment for walking and the development and use of audits in organisational contexts. State (Australia) and national

\footnotetext{
${ }^{1}$ We acknowledge that local governments and community groups are not limited to using only those tools promoted to them by national and state jurisdictions but it was beyond the scope of this research to investigate the range of possible tools used at local government level.
} 
(New Zealand) transport agencies and planning organisations promoting audit tools were contacted to identify audit developers and those that had used the audit tools in various planning contexts. Given that built environment auditing is an emerging practice in Australia and New Zealand there are few professionals currently active. Ten professionals were identified and participated in the interviews, representing the total number of New Zealand and Australian state transport agencies currently promoting auditing the built environment for walking. The interviews were semi-structured, lasting between forty-five minutes and one hour. Initial questions were framed around themes - organisational roles; problem framing relevant to walking; defining knowledge of audits; and auditing practices - and the responses to these initial questions dictated the scope of further questions.

The interviewees were professionals employed either as travel behaviour change officers $^{2}$, walking advocates, or as transport policy officers, engineers and planners involved with projects related to improving the quality of streets for walking. One of the walking advocates was involved in a government funded, charity organisation, and the other was involved in an advocacy group as a volunteer. Six of the ten interviewees had developed audits for their organisation. Of these, only three had knowledge of audits being used in real-life contexts. Two of the three had knowledge of examples of their audits being used by local government planners or community members. The other

\footnotetext{
${ }^{2}$ Travel behaviour change officers were established by the State Department of Transport (Western Australia) in the 1990s as part of the introduction of a TravelSmart program set up to implement new mode share targets aimed at car travel reduction. The TravelSmart program is now Australia-wide with officers employed at both State and Local Government levels. See http://www.transport.wa.gov.au/activetransport/24607.asp.
} 
interviewee had used an audit to conduct a comprehensive program of auditing of the built environment around schools in a local government area. Four of the ten interviewees, including all three travel behaviour change officers, promoted audits within their organisation and could articulate ideas about the potential for audits to be used in policy settings, yet had no knowledge of their actual use. Although a limited selection of professionals were identified as having knowledge of auditing for walking, the findings are relevant to a broader range of professional roles in the government and community sectors who have the potential to use audits, including urban designers, planning consultants and community groups. Table 1 outlines the roles, responsibilities and knowledge of audits of each of the interviewees.

[Insert Table 1]

A thematic analytic approach was used to analyse the interview data (Boyatzis, 1998). Thematic analysis allowed inferences to be made from interviews and a broader framework related to the institutional context of planning for walking. The interviews were transcribed and entered into Hyperresearch Version 3.5.2., a qualitative data analysis software package that allowed statements from the interviews to be assigned codes or multiple codes, and for the codes and coded data to be extracted and analysed. The themes related to the institutional contexts of auditing for walking emerged through the categorization, sorting and analysis of codes (Saldana, 2013). The thematic analysis allowed a comparison across the different professional groups of how auditing practices were perceived to be useful and how audits had been used. 


\section{Findings}

\section{Walking audits: content}

The audit tools available to planners in ANZ evaluate a range of built environment characteristics relevant to walking. The tools rated street segments using a mix of subjective responses to built environment elements, quantitative measures of the presence of supportive infrastructure and indications of the level of activity on the road and on the pathways. A variety of physical built environment and spatial factors were captured - physical factors referring to the infrastructure for walking, and the operational factors referring to the movement of traffic, cyclists and other pedestrians. Each of the audits focused on domains identified as fundamental to walking (Alfonzo, 2005; Southworth, 2005) including safety, the presence of supportive infrastructure, the quality of road crossings, and the aesthetic quality of mobility environments. In this way, the audits represented simplified forms of audit tools such as SPACES (Pikora et al., 2002), IMI (Day et al., 2006) and PEDS (Clifton et al., 2007) used by planning and public health researchers. Most of the audits contained questions that considered the built environment from a number of perspectives - from the point of view of children, elderly and wheelchair users. The review of audit tools detailing the characteristics of the audits is outlined in Table 2.

[Insert Table 2]

\section{Walking audits: perceptions}

Walkability audits were considered useful in addressing issues related to walking by all interviewees, however they were identified as beneficial in different ways. Audits' 
ability to quantify 'walkability' was their primary purpose according to traffic engineers and transport planners. Audits, according to TE\#2 and the TPO\#1, could measure a formal quality of the walkability of an area and this could then contribute to an evidence base that would inform the provision of pedestrian infrastructure. According to TBC \#2, “you know exactly what you've got. You're not making subjective arguments”. Precision was valued, reflecting the 'culture of objectivity' (Porter 1995) that has developed due to the explosion of quantification methods and tools that synthesize complex information into manageable forms of knowledge.

Audits also enabled the benchmarking of built environment quality for walking against 'best practice'. The transport policy officer described how his department's audit was shaped by external design standards: "the criteria that the audit addressed fitted within the Austroad design standards (TPO\#1).” Both the New Zealand Transport Agency’s Community Street Review and Western Australian Department of Transport's Walkability Audit Tool contained references to extensive supporting technical guidelines and design standards. Measurement and benchmarking reflect the quantitative function of audits. The ability to reduce complexity through quantification reflected a symbolic resource auditors drew upon to legitimise auditing practices (Power, 1995).

Walkability audits were also perceived by some interviewees to be useful in prioritising interventions and allocating funding to projects within their agencies' jurisdictions. TP\#2 described a program she was employed on as a consultant by a local government, involving the auditing of all streets surrounding primary schools in the municipality. Walking to school is an important means for children to engage in regular active travel, 
increase the independent mobility and allow opportunities for social engagement (Mitra, 2012). The auditing approach was enlisted as a means to prioritise schools according to their need for pedestrian infrastructure. Before the auditing process the local government was responding to the requests for infrastructure in the order that they were lodged, “effectively running through their budget until the money ran out (TP\#1)”. The audit program was introduced to evaluate and prioritise resource allocation in anticipation of questions about infrastructure provision by the schools. While this process was effective in allocating resources (illustrating the popularity of audits more broadly within contemporary neoliberal institutions), these were resources previously committed to improving the built environment around schools. The use of walking audits in this way allows the allocation or redistribution of resources with the aim to increase organisational efficiencies and productivity (Shore and Wright, 1999). The question of whether auditing adequately addresses the current and future needs of local communities was not however articulated.

Audits also served a collaborative function. For the travel behaviour change officers and advocates, audits could draw together a range of stakeholders in a process of collective evaluation. This function of auditing was valued by the advocates, who referred to the potential for audits to enable collaboration between differing knowledgebased actors within walking environments, drawn from the political, community and technical realm.

So that (auditing) is not just "well, here there's another bunch of whingeing community members", we'd like to involve the councillor and even the Chamber of Commerce (WA\#2). 
Through the practical conduct of auditing, relevant knowledge of community, political and business interests would be integrated producing an evaluation that was greater than the sum of the different parts. There is a potential role therefore for integrating auditing into participatory local planning practices. However, as MacCallum (2008) notes, in participatory processes that involve the transfer of meaning from arenas outside the bureaucracy into the formal technical processes or instruments of the bureaucracy, a reframing of knowledge occurs that often negates the shared knowledge generated through collaboration. Knowledge generated by walking audits therefore risks being reframed in ways that inadequately challenge the path dependency of automobile dominant transport bureaucracies.

The ability of audits to integrate knowledge types within a formal technical instrument also legitimised civic organisations involved in improving the urban environment for walking. By conducting an audit, community-based organisations would approach their local environments with an ordered evaluative framework. Advocates drew on the audits' symbolic resources of scientific process and quantification as they enabled the translation of localized knowledge of walking environments into the technical frameworks valued by transport planners and engineers. WA\#1 stated: “audits are really key for an organisation like us because they enable us to punch above our weight.” Audit knowledge is legitimate in the public domain and this can be used to add weight to arguments within the political realm.

If the council says why did you put shade in that street, instead of just saying "we just did”, we can now say that we had analyzed the street and found that it needed street trees. We can back up our decisions (TBC\#1). 
When the contingent knowledge produced by audits is abstracted and formalised, outsiders are able to claim this knowledge as their own and hence challenge the orthodoxy. This is an important strategy for planners seeking to improve the urban environment for walking. Finally, walking audits were valued by the advocates as a means of providing a transformative experience of evaluation for each individual auditor. For example, WA\#1 saw audits as playing a role in getting people to "start looking a their neighbourhood differently.” According to TP\#1, the experiential knowledge of the local context provided by the act of auditing was as important as the technical findings of an audit.

We weren't doing things like vehicle counts because we didn't have the budget to do it. It was more of an observational feel for, "yes, this is running well”. You get an idea pretty quickly about what is good and bad (TP\#1).

The direct and tacit knowledge of context is important, highlighting the formative role the auditor has in shaping the direction of audit practice. In this way auditing for walking shares common traits with a "neighbourhood inquiry" as described by Neil Gray (2013) in a recent Interface, where audit evaluation becomes a immanent, collective social inquiry and can potentially address the real concerns of neighbourhood residents rather than relying on market-led ideas of sustainable urban environments.

\section{The use of built environment audits for walking}

The qualities of audits as described by audit developers and practitioners, in part shape the capacity of the various epistemic communities to improve planning for walking. Institutions also shape auditing practices. The influence of institutional contexts was primarily evident in the responses regarding the resources available to practitioners to conduct auditing practices. As well as providing transport planners and engineers a means to manage and prioritise internal budget commitments, audits were described as 
resource intensive. This has been a key theme in research that assesses the reliability of audits and some researchers have suggested that audits should be simplified in order to be more practical for planning practitioners and community advocacy (Hoenher et al., 2006). However, there were more systemic problems related to funding that created more significant barriers to widespread auditing practices. Some of the organisations' funding arrangements created situations where walking and cycling competed for their share of money from a common budget: “cycle ways can chew up your money pretty quickly” (TBC\#2). To operate effectively within these institutional contexts, auditors described less resource intensive strategies and methods that could be employed to augment the limited existing audit capabilities. These include desktop surveys to analyse the broader walkable catchment conditions, and a general interest in exploring technological capacities of other instruments, such as GIS, GPS and smartphones. Travel behaviour change officers and advocate groups used web-based communication to promote audits.

There was a suggestion evident in the transport engineers' responses that audit technologies were developing in a way that could improve their resource efficiency. One transport engineer described how better technologies and models were used to develop a resource intensive community-based audit that captured people’s perceptions of the quality of the built environment, into a more technical audit, one that could: ...predict how people perceive their built environment based on some physical and operational measures... you can then send one technician around and measure the whole of the network. You can come up with a map that talks about Level of Service (TE \#2). 
The audit tool provided practical efficiencies by avoiding the need for collective evaluation of walking environments, but in doing so shifted the evaluative process away from the realm of localised, direct knowledge of urban environment environments and into the technical domain.

The gravitation of audit programs into the technical domain of transport engineering was also evident in the strategic positioning of auditors to access resources in other departments or agencies, creating better opportunities to employ audit programs. For example, referring to the difficulties in implementing programs that use audits to effectively improve the quality of built environments for walking and increase rates of walking, TP\#1 commented:

The other issue, which is an internal budgeting issue, is that travel plans or travel behaviour change work are often done by people in planning, environment or sustainability sections of local government, and the money isn't there. The money is with traffic engineering, because the money is there to build things (TP\#1).

The capacity to enact audit programs was also hindered by the governing political powers. The advocates and one transport planner referred to recent changes in government that had changed the level of commitment and landscape of opportunity for transport planners concerned with walking; "Walking and walkability are off the agenda” noted the transport planner. Another stated: "walking as a political idea is nowhere in Queensland at the moment”. The predominant challenges for transport planners and engineers in the current political climate saw auditing practices put to work efficiently and prioritizing allocation of resources at the organisational level. Used 
in this way audits were primarily used for the rational allocation of scarce resources rather than tools that lead to substantive changes in the built environment for walking.

In enabling a bridge between the experience of local citizens and the normative function of walkability audits, audits were valued by the advocates and travel behaviour change officers as a means for community members to make legitimate claims for resources to address problems in their local walking environments. In increasingly neoliberal urban institutions where public services and infrastructure are delivered to meet demand, there is therefore a clear role for audits to articulate community demand for good quality and safe walking environments. Spence (2009) draws attention to the emancipatory potential of traditional accounting techniques when used by civil society organisations to make accountable the social and ethical consequences of hegemonic power. Audits, measurements and standards, according to Power (2004, p.774), are “imperfectly democratic, but democratic nonetheless”. The 'tools of the trade' of governing institutions can be acquired and employed to legitimise the claims of those outside formal governing institutions.

There were barriers however to more civic participation in auditing practices evident in the interviews. Community members' concerns were perceived by actors within government organisations to not fit within the existing resource commitments and therefore were framed as problematic. Local knowledge and civic participation were described by one engineer as a community street audit where you bring together "a whole lot of people on the side of the road and you have a bit of a bitch and moan” (TE\#2). Whilst not unimportant, local knowledge was instead considered by TE\#2 too impractical to incorporate into auditing practices. Despite the value in a consumer 
perception audit approach to gathering local knowledge, the process to capture "the whole network” was too expensive. The technical realm of auditing was identified as less resource intensive than the local or community realm, although the latter was valued as more 'real' and 'relevant' to understanding built environment quality for walking. TP\#1, who was involved in the auditing of school built environments, considered it important that the audit findings were not revealed to the school as there was a risk that the school's expectations would be raised that infrastructure would be provided.

Now the reason the council didn't want to give the schools the audits was that they didn't want to raise false expectations. So schools couldn't say:

"Well, we need this crossing because you've identified this in your audit. And therefore we're going to start phoning you every day to get it” (TP\#1).

In contrast to the way advocates valued audits, here the value of audits was their ability to depoliticize local knowledge. Audits were to be conducted covertly within a formal institutional setting, avoiding the potential for community expectations to be raised. Local knowledge was considered impractical, as it was likely not to be acted on. Despite the rhetoric of the 'emancipatory potential', or bottom-up governance of auditing practices, in the examples of actual audit programs for walkability provided by the interviewees, formal institutions retained control over the auditing process and participation by local citizens was restricted.

\section{Conclusion}

The questions underpinning this research focus on the activity of auditing the built environment for walking - who uses audits, how are they used, and what substantive changes emerge from an auditing practice? The value of audit tools is in their capacity to evaluate the quality of built environment for walking and instigate substantive 
changes in the built environment that may lead to increased rates of walking. The audit tools available in ANZ contain categories and metrics that capture issues such as safety, the connectivity of paths and aesthetics of the built environment. The small selection of audits assessed in this research shared commonalities with a broader ranges of audit tools that the research literature suggests reliably capture built environment qualities that are important for walking (Day et al., 2006; Hoehner et al., 2006; McMillan 2010). The potential for audit tools to lead to substantive changes to the built environment, however, is dependent on planner's activity in their institutional contexts.

The literature on audit culture provides insights into the transport institutions that shape the practices employed, rules, norms and capacity of agents to act and use audit tools to improve the quality of built environments and thence the number of people walking. The interview findings demonstrate that audit tools were considered valuable by transport engineers and transport planners for measuring walkability to know what infrastructure to build, how important it was to build and how budgets could be allocated accordingly. Characteristic of audit culture in general, as described by Power (1995), transport engineers and planners drew on audits' status as scientific instruments within transport organisation and bureaucracies, providing a rational framework for measuring walkability. Their capacity to systematically capture the built environment features and link to technical benchmarks and standards of best practice gave them weight in planning practice, policy formation and the political realm. Alternatively, audits were considered as tools for collaborative evaluation, a means to enhance the legitimacy of effort to improve walkability, and an evaluative experience by travel behaviour change planners and walking advocates. The advocacy position identified audit practice as strategic, firmly embedded within the political realm. Audits were 
tools that gave community groups greater legitimacy, empowering them with scientific and technical knowledge to address either the 'single issue', focused on one off sites of contention, such as a dangerous crossing, or broader campaigns focused on 'liveability' and 'good quality streets'. Reflecting notions of auditing as a democratic practice, political arguments according to the advocacy interviewees, could be won through using audits and drawing on their status as symbolic resources of good scientific practice.

From the positive responses to auditing highlighted by the interviewees there appears to be multiple roles for built environment audits in realizing multi-modal cities. However, when addressing the question - how are audits used? - the potential of built environment audits is less clear. Insight from the audit culture literature and responses from the interviewees highlight some problematic issues for audits to realize the potential identified by the different epistemic communities of planning for walking (Power, 1995; Power, 2004; Shore and Wright, 1999). The tendency for transport engineers and planners to prioritise technical knowledge over the local knowledge of communities in order to minimise organisational resources allocated to auditing programs highlights a risk that audits could operate as purely technical instruments without any meaningful interaction with the contingent socio-spatial contexts where walking takes place. The improved calibration of audit instruments through technological advances is unlikely to lead to substantive changes to the quality of built environment for walking or increasing rates of walking without broader political support and commitment of resources. This is because audits perform a secondary function to advancing planning for walking in that they function as tools that rationalise allocation of existing resources to identified problems rather than providing insight into 
whether the amount of resources needed to address issues identified by auditors was enough.

While the literature provides evidence that audits are effective means to measure the physical attributes that are supportive of walking, theories regarding audit culture raise the important question of: to what ends do audits serve? The prioritization of the technical function of built environment auditing and the use of audits to depoliticise local concerns regarding demands for pedestrian infrastructure, characterized the most extensive program of actual auditing that the researchers could identify. This is concerning because it confirms that the opportunities for auditing programs in current institutions are primarily based on the quality of audits as a means to deliver organisational efficiency, emblematic of a broader neo-liberal audit culture. As long as transport and land use planning institutions continue to prioritise the allocation of resources to maintaining automobility there is a risk of audit tools will remain primarily tools that discipline auditors, organisations and agencies to be efficient and productive without addressing the question of what substantive changes emerge from audit practices that could lead to more sustainable, multi-modal models of urban transport.

While these findings report the ANZ experience of auditing for walking, pathways for planners using audits to produce substantive changes to the quality of the built environment for walking are evident. Firstly, walking audits have the potential to integrate local knowledge and civic institutions within formal institutional structures that shape the quality of the streets and environments for walking. Secondly, as promoters and commentators on audit culture note, audits can be utilised to improve the transparency and quality of institutional practices and outcomes. However, current 
practice indicates that built environment auditing has a limited role to play in leading to substantive changes in urban environments for walking, challenging the dominant modes of automobility to make substantive improvements to walking environments. Critical attention needs to be paid to the audits' role as political instruments, used to leverage funding and policy attention to walking issues. This is particularly so in relation to their role as technical instruments where they serve a more rational function of ordering and organising resources. Paying attention to the broader institutional context that audits operate within and understanding their relationship with organisational capacities will provide a more accurate sense of the potential for audits to advance planning for walking. It is at the institutional scale that many of the tradeoffs between automobility and alternative modes of mobility are made. This is important because, although built environment audit use is not widespread, this research indicates audits have the capacity to play a role in the planning, monitoring and evaluation of the built environment for walking.

\section{Acknowledgments}

This research was funded by an Australian Research Council Discovery Grant (DP1094495). We would like to thank all interviewees for their time and insights. We also acknowledge and appreciate the constructive feedback provided by three anonymous reviewers and editors.

\section{References}

1. Appleyard, D. (1972). The environmental quality of city streets, Journal of the American Planning Association, 35, 84-101.

2. Alfonzo, M. A. (2005). To Walk or Not to Walk? The Hierarchy of Walking Needs. Environment and Behaviour, 37(6), 808-836. 
3. Banister, D. (2002). Transport Planning, London: Spon.

4. Banister, D. (2008). The sustainable mobility paradigm. Transport Policy, 15(2), 73-80.

5. Beckmann, J. (2004). Mobility and safety. Theory, Culture \& Society, 21(4 5), 81-100.

6. Blomley, N. (2007). How to turn a beggar into a bus stop: Law, traffic and the 'function of the place'. Urban Studies, 44(9), 1697-1712.

7. Blomley, N. (2010). Rights of Passage: Sidewalks and the Regulation of Public Flow. Hoboken: Taylor and Francis.

8. Booth, C., \& Richardson, T. (2001). Placing the public in integrated transport planning. Transport Policy, 8(2), 141-149.

9. Boyatzis, R. E. (1998). Transforming qualitative information: thematic analysis and code development. Thousand Oaks, CA: Sage Publications.

10. Brog, W., Erl, E., Ker, I., Ryle, J., \& Wall, R. (2009). Evaluation of voluntary travel behaviour change: Experiences from three continents. Transport Policy, 16(6), 281-292.

11. Christian, H., Knuiman, M., Bull, F., Timperio, A., Foster, S., Divitini, M., Maddington, N. \& Giles-Corti, B. (2013). A New Urban Planning Code's Impact on Walking: The Residential Environments Project. American Journal of Public Health, 103(7), 1219-1228.

12. Clifton, K. J., Livi Smith, A. D., \& Rodriguez, D. (2007). The development and testing of an audit for the pedestrian environment. Landscape and Urban Planning, 80(1-2), 95-110.

13. Curtis, C. (2001) Future Perth: Transport Issues and Options. Perth, Western Australian Planning Commission. 
14. Curtis, C., \& Low, N. (2012). Institutional Barriers to Sustainable Transport. Surrey: Ashgate,

15. Curtis, C., Punter, J. V. 2004. Design-Led Sustainable Development: The Liveable Neighbourhoods Experiment in Perth, Western Australia. Town Planning Review Vol 75 (1), 116-150.

16. Curtis C and Tiwari R (2008) Transitioning Arterial Roads to Activity Corridors. Urban Design International Vol 13 (2), 105 -120.

17. Day, K., Boarnet, M., Alfonzo, M., \& Forsyth, A. (2006). The Irvine-Minnesota Inventory to Measure Built Environments: Development. American Journal of Preventive Medicine, 30(2), 144-152.

18. Dudley, G., \& Richardson, J. (1996). Why does policy change over time? Adversarial policy communities, alternative policy arenas, and British trunk roads policy 1945-95. Journal of European Public Policy, 3(1), 63-83.

19. Fischer, F. (2003). Reframing public policy: discursive politics and deliberative practices. Oxford: Oxford University Press.

20. Gehl, J. (2010). Cities for People, Washington, DC: Island Press.

21. Giles-Corti, B., \& Donovan, R. (2002). The relative influence of individual, social and physical environment determinants of physical activity. Social Science \& Medicine, 54, 1793-1812.

22. Gleeson, B., \& Low, N. (2000). 'Unfinished Business': Neoliberal Planning Reform in Australia. Urban Policy and Research, 18 (1), 7-28.

23. Gray, N. 2013. "Neighbourhood Inquiry”: For a Post-Political Politics. In Porter, L. (ed), Finding Hope in Unpromising Times: Stories of Progressive Planning Alternatives for a World in Crisis. Planning Theory \& Practice 14 (4): 529-529. 
24. Gray, R. (2002). The social accounting project and Accounting Organisations and Society Privileging engagement, imaginings, new accountings and pragmatism over critique? Accounting, Organisations and Society, 27(7), 687708.

25. Haas, P. (1992). Introduction: epistemic communities and international policy coordination. International Organisation, 46(01), 1-35.

26. Hagman, O. (2006). Morning Queues and Parking Problems. On the Broken Promises of the Automobile. Mobilities 1 (1): 63-74.

27. Hoehner, C., Ivy, A., Ramirez, L., Meriwether, B., \& Brownson, R. (2006). How Reliably Do Community Members Audit the Neighborhood Environment for Its Support of Physical Activity? Implications for Participatory Research. Journal of Public Health Management \& Practice, 12(3), 270-277.

28. Ingold, T. (2011). Being alive: essays on movement, knowledge and description. London: Routledge.

29. Kent, J. (2014). Driving to Save Time or Saving Time to Drive? The Enduring Appeal of the Private Car. Transportation Research Part A: Policy and Practice, 65, 103-115.

30. Kim, S., Choi, J., \& Kim, S. (2013). Roadside walking environments and major factors affecting pedestrian level of service. International Journal of Urban Sciences, 17(3), 304-315.

31. Lewis, F. (2012). Toward a general model of built environment audits. Planning Theory, 11(1), 44-65.

32. Lyons, R. A., Kendrick, D., Towner, E. M. L., Coupland, C., Hayes, M., Christie, N., Sleney, J., Jones, S., Kimberlee, R., Rodger, S. E., Turner, S., Brussoni, M., VinogradovaI, Y., Sarvotham, T. \& Macey, S. (2013). The 
Advocacy for Pedestrian Safety Study: Cluster Randomised Trial Evaluating a Political Advocacy Approach to Reduce Pedestrian Injuries in Deprived Communities. PLoS One, 8. 8(4).

33. MacCallum, D. (2008). Participatory Planning and Means-Ends Rationality: A Translation Problem. Planning Theory \& Practice, 9(3), 325-343.

34. Martin, G. (2002). Grounding Social Ecology: Landspace, Settlement, and Right of Way. Capitalism Nature Socialism, 13(1), 3-30.

35. McCann, B. (2013). Complete Streets: The transition to safe and inclusive transportation networks. Washington: Island Press.

36. McMillan, T., Cubbin, C., Parmenter, B., Medina, A., \& Lee, R. (2010). Neighborhood sampling: how many streets must an auditor walk? International Journal of Behavioural Nutrition and Physical Activity, 7(20), 1-5.

37. Mees, P. (2010). Transport for suburbia: beyond the automobile age, London: et alEarthscan.

38. Mees, P., and Groenhart, L. (2014). Travel to Work in Australian Cities: 19762011."Australian Planner 51 (1), 66-75.

39. Merriman, P. (2006). 'Mirror, Signal, Manoeuver': assembling and governing the motorway driver in late 1950s Britain in Bohm, S., Jones, C., Land, C. and Paterson, M. (2006). Against Automobility. Malden, MA: Blackwell Publishing. 40. Mitra, R. (2013) Independent Mobility and Mode Choice for School Transportation: A Review and Framework for Future Research. Mobilities. 33 (1), 21-43.

41. Moudon, A., \& Lee, C. (2003). Walking and Bicycling: An Evaluation of Environmental Audit Instruments. American Journal of Health Promotion, 18(1), 21-37. 
42. Patton, J. W. (2007). A pedestrian world: competing rationalities and the calculation of transportation change. Environment and Planning A, 39(4), 928944.

43. Pikora, T., Bull, F., Jamrozik, K., Knuiman, M., Giles-Corti, B., \& Donovan, R. (2002). Developing a reliable audit instrument to measure the physical environment for physical activity. American Journal of Preventive Medicine, 23(3), 187-194.

44. Porter, T. (1995). Trust in numbers: the pursuit of objectivity in science and public life. Princeton, N.J.: Princeton University Press.

45. Power, M. (1995). Auditing, Expertise and the Sociology of Technique. Critical Perspectives on Accounting, 6(4), 317-339.

46. Power, M. (1997). Expertise and the construction of relevance: Accountants and environmental audit. Accounting, Organisations and Society, 22(2), 123-146.

47. Power, M. (2004). Counting, control and calculation: reflections on measuring and management. Human Relations, 57(6), 765-783.

48. Richards, R., Murdoch, L., Reeder, A. I., \& Rosenby, M. (2010). Advocacy for active transport: advocate and city council perspectives. International Journal of Behavioural Nutrition and Physical Activity, 7.

49. Rietveld, P., \& Stough, R. (2004). Barriers to sustainable transport: institutions, regulation and sustainability. London: Spon Press.

50. Rose, E., Witten, K. and McCreanor, T. (2009). Transport Related Social Exclusion in New Zealand: Evidence and Challenges. Kötuitui: New Zealand Journal of Social Sciences, 4 (3), 191-203. 
51. Rydin, Y., Amjad, U., \& Whitaker, M. (2007). Environmentally Sustainable Construction: Knowledge and Learning in London Planning Departments. Planning Theory \& Practice, 8(3), 363-380.

52. Saldaña, J. (2012). The coding manual for qualitative researchers (2nd ed.). London: Sage Publications.

53. Schwanen, T., Banister, D., \& Anable, J. (2012). Rethinking habits and their role in behaviour change: the case of low-carbon mobility. Journal of Transport Geography, 24(0), 522-532.

54. Shore, C. (2008). Audit culture and Illiberal governance Universities and the politics of accountability. Anthropological Theory, 8(3), 278-298.

55. Shore, C., \& Wright, S. (1999). Audit Culture and Anthropology: NeoLiberalism in British Higher Education. The Journal of the Royal Anthropological Institute, 5(4), 557-575.

56. Shoup, D. 2011. The High Cost of Free Parking, Chicago: American Planning Association.

57. Shove, E. (2010). Beyond the ABC: climate change policy and theories of social change (attitude, behaviour, and choice). Environment \& Planning A, 42(6), 1273-1285.

58. Southworth, M. (2005). Designing the Walkable City. Journal of Urban Planning and Development, 131(4), 246-257.

59. Spence, C. (2009). Social accounting's emancipatory potential: A Gramscian critique. Critical Perspectives on Accounting, 20(2), 205-227.

60. Steg, L. (2005). Car use: lust and must. Instrumental, symbolic and affective motives for car use. Transportation Research Part A, 39(2), 147-162. 
61. Taylor, M., \& Ampt, E. (2003). Travelling smarter down under: policies for voluntary travel behaviour change in Australia. Transport Policy, 10(3), 165177.

62. Tiesdell, S., \& Adams, D. (2011). Urban design in the real estate development process. Ames, Iowa: Wiley-Blackwell.

63. Urry, J. (2004). The 'system' of automobility. Theory, Culture \& Society, 21(4 5), 25-40.

64. Webb, J. (2012). Climate Change and Society: The Chimera of Behaviour Change Technologies. Sociology, 46(1), 109-125.

65. Whitelegg, J. (1997). Critical mass: transport, environment and society in the twenty-first century. London: Pluto Press.

66. Zhang, Y., Stopher, P., \& Halling, B. (2009). An Evaluation of TravelSmart Tools for Travel Behaviour Change. Paper presented at the Australian Transport Research Forum, Auckland, New Zealand. 
Table 1: Summary of interviewees

\begin{tabular}{|c|c|c|}
\hline Epistemic community & Responsibility & Experience with audits \\
\hline $\begin{array}{l}\text { Walking advocate \#1 } \\
\text { (WA\#1) }\end{array}$ & Independent & Developed audit; knowledge of use \\
\hline $\begin{array}{l}\text { Walking advocate \#2 } \\
\text { (WA\#2) }\end{array}$ & Independent & Knowledge of audits \\
\hline $\begin{array}{l}\text { Transport engineer \#1 } \\
\text { (TE\#1) }\end{array}$ & State/ national & Developed an audit \\
\hline $\begin{array}{l}\text { Transport engineer \#2 } \\
\text { (TE\#2) }\end{array}$ & State/ national & Developed an audit \\
\hline $\begin{array}{l}\text { Transport planner \#1 } \\
\text { (TP\#1) }\end{array}$ & Consultant & $\begin{array}{l}\text { Developed an audit; conducted an audit } \\
\text { program audit }\end{array}$ \\
\hline $\begin{array}{l}\text { Transport planner \#2 } \\
\text { (TP\#1) }\end{array}$ & Consultant & Developed an audit; knowledge of use \\
\hline $\begin{array}{l}\text { Travel behaviour change } \\
\text { officer \#1 (TBC\#1) }\end{array}$ & $\begin{array}{l}\text { Metropolitan } \\
\text { scale }\end{array}$ & $\begin{array}{l}\text { Knowledge of audits; organisation promotes an } \\
\text { audit }\end{array}$ \\
\hline $\begin{array}{l}\text { Travel behaviour change } \\
\text { officer \#2 (TBC\#2) }\end{array}$ & $\begin{array}{l}\text { Metropolitan } \\
\text { scale }\end{array}$ & $\begin{array}{l}\text { Knowledge of audits; organisation promotes an } \\
\text { audit }\end{array}$ \\
\hline $\begin{array}{l}\text { Travel behaviour change } \\
\text { officer \#3 (TBC\#3) }\end{array}$ & $\begin{array}{l}\text { Metropolitan } \\
\text { scale }\end{array}$ & $\begin{array}{l}\text { Knowledge of audits; organisation promotes an } \\
\text { audit }\end{array}$ \\
\hline $\begin{array}{l}\text { Transport policy officer } \\
\text { \#1 (TPO\#1) }\end{array}$ & $\begin{array}{l}\text { Metropolitan } \\
\text { scale }\end{array}$ & Developed an audit \\
\hline
\end{tabular}


Table 2: Review of audit tools (Sources: http://www.nzta.govt.nz/resources/community-street-reviews/docs/csr-guide.pdf; http://www.victoriawalks.org.au/Walking_audit/; http://www.queenslandwalks.org.au/;

http://www.heartfoundation.org.au/SiteCollectionDocuments/HFW-Walkability-Checklist.pdf; www.tmr.qld.gov.au/ /media/busind/.../trum/TRUMVolume3311.pdf; http://www.transport.wa.gov.au/mediaFiles/active-transport/AT_WALK_P_Walkability_Audit_Tool.pdf)

\begin{tabular}{|c|c|c|c|c|c|c|}
\hline Audit & Source & Categories of measures & $\begin{array}{c}\text { Evaluative } \\
\text { method }\end{array}$ & Overall rating/output & Unit of analysis & Different groups included \\
\hline Community & New & Categories include safety from traffic; & Rating from very bad & Review is to provide & Route. Street & Participant information section \\
\hline \multirow[t]{3}{*}{ Street Review } & Zealand & safety from falling; obstacle free; & to very good, each & supporting evidence in a & section/segment. Two & asks question whether the \\
\hline & Transport & secure; pleasant; efficient; delay; and & with example & submission to authorities. & elements: path length and & auditor could walk unaided. \\
\hline & Agency & direct. & statements. & & crossing. & \\
\hline Walking Audit & Victoria & Six categories are identified, each & Rating from 0 to & No overall rating. Findings & Route, but area and specific & One rating identifies the issue as \\
\hline \multirow[t]{4}{*}{ Form } & Walks and & with a number of related issues: & 3. Space provided & are to inform a report, based & location can be evaluated. & relevant to children, elderly or \\
\hline & Queensland & footpaths; facilities; crossing the & for auditor & on whether the issue will be & & people in prams. \\
\hline & Walks & road; traffic; safety (personal); and & observation. & a problem for no-one, some & & \\
\hline & & aesthetics & & people or everyone. & & \\
\hline
\end{tabular}




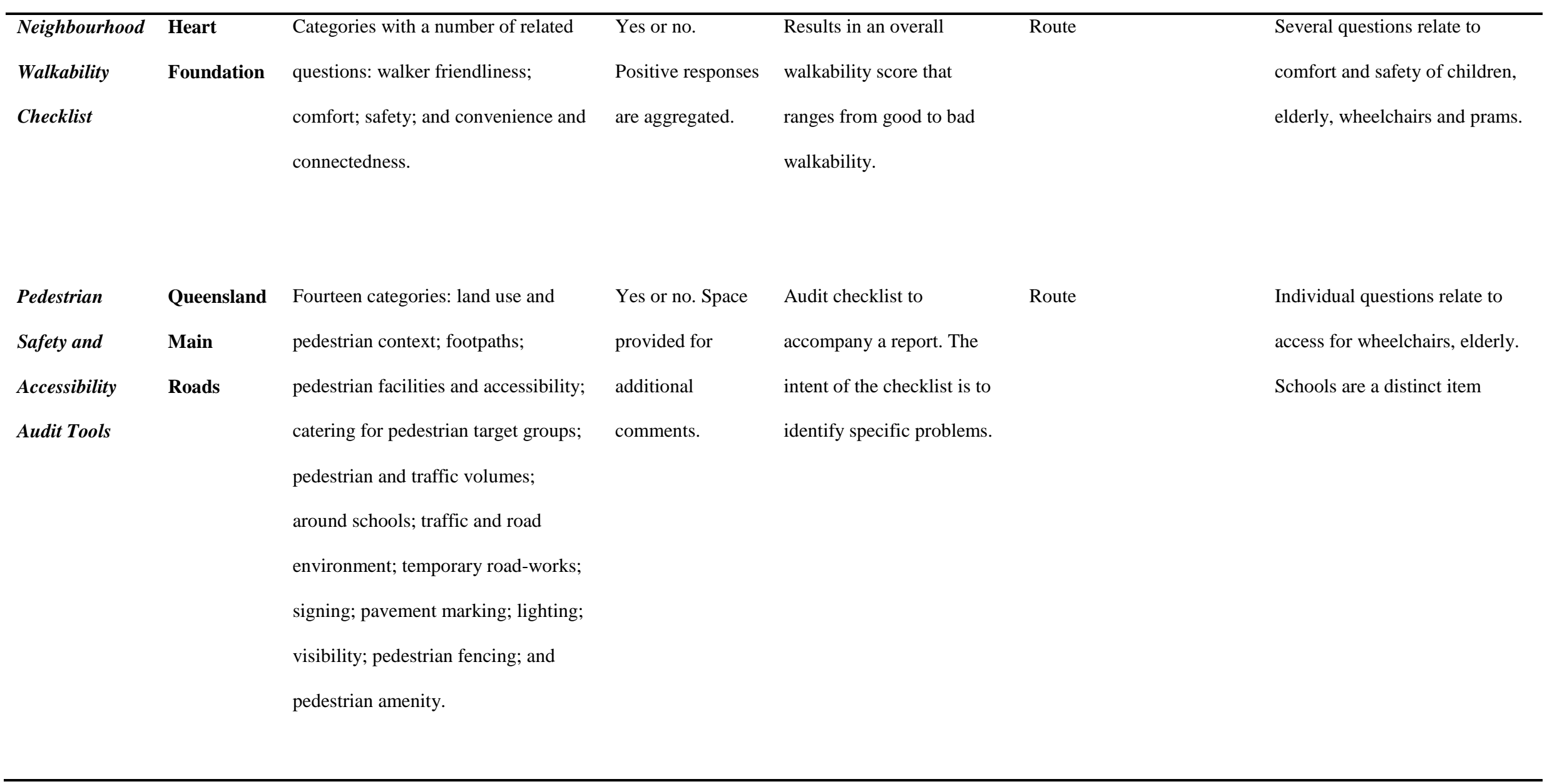




\begin{tabular}{|c|c|c|c|c|c|c|}
\hline Walkability & Western & Seven categories: overall impression; & Yes or no, and & Audit is to accompany a & Section, identified on a & Contains questions that require \\
\hline \multirow[t]{5}{*}{ Audit Tool } & Australian & pathways; crossings; street furniture & rating: & report. The report template & map. Routes are evaluated & the auditor to evaluate path \\
\hline & Department & and signage; personal safety; adjacent & unsatisfactory/ & is provided. & in the section. & accessibility, crossings and \\
\hline & of & traffic; and aesthetics. & unsatisfactory but & & & visibility from the perspective \\
\hline & Transport & & acceptable; and & & & of children. \\
\hline & & & satisfactory. & & & \\
\hline
\end{tabular}


